\title{
Do lithium disilicate ceramic manufacturing techniques affect the degree of conversion of light-cured resin cement?
}

\author{
Amauri Cruz Drumond, Sandrine Bittencourt Berger, Alejandra Hortencia Miranda González, \\ Guilherme Genovez-Júnior, Lucineide Lima dos Santos, lana de Oliveira Fernandes Drumond, \\ Murilo Baena Lopes and Ricardo Danil Guiraldo* (1)
}

*Correspondence:

rdguiraldo@gmail.com

Department of Restorative Dentistry, School of Dentistry,

University of North Parana (UNOPAR), Rua Marselha,

183, Londrina, PR 86041-140, Brazil

\begin{abstract}
The aim of this study is to evaluate the degree of conversion of light-cured resin cement subjected to activation through the interposition of lithium disilicate ceramic produced according to two manufacturing techniques. Cylindrical specimens of Rely $X^{\mathrm{TM}}$ Veneer resin cement were generated based on each manufacturing technique (CAD/CAM — computer aided design/computer assisted manufacturing, $n=5$ or pressed ceramic technique, $n=5$ ). Next, the specimens were washed in distilled water, dried with absorbent paper and stored in containers filled with distilled water at $37^{\circ} \mathrm{C}$ for $24 \mathrm{~h}$. Specimens from each group were subjected to attenuated total reflectance Fourier transform infrared (ATR-FTIR) in order to evaluate their degree of conversion. Data about the degree of conversion (\%) were subjected to analysis of variance and to Student's t-test $(a=0.05 \%)$. The degree of conversion of Rely ${ }^{\mathrm{TM}}$ Veneer was statistically higher in the CAD/CAM manufacturing technique (39.83 $\pm 0.35 \%)$ than in the Press one $(37.59 \pm 0.62 \%)$. The light-cured resin cement activated through ceramic structure reinforced with lithium disilicate generated through the CAD/CAM manufacturing technique showed higher degree of conversion than the one generated through the Press manufacturing technique.
\end{abstract}

Keywords: Ceramics, Resin cements, Cementation, Polymerization

\section{Introduction}

The use of ceramic veneers in Dentistry has increased due to high degree of aesthetic requirements, since lithium disilicate veneers can restore dental aesthetics in a way to make it look very similar to the natural dental structure, besides requiring less invasive or even no cavity preparation [1]. However, the aesthetic quality of the material is not the only criterion to be taken into consideration at the time to assure successful restoration procedures, since ceramic veneers must firmly adhere to the dental structure through resin cements [2]. The commercially available cements for laminate restoration luting may be light or dual-cure activated. Some advantages such as color stability, working time and ease of use make the photopolymerizable cement the material of choice

(c) The Author(s) 2018. This article is distributed under the terms of the Creative Commons Attribution 4.0 International License (http://creativecommons.org/licenses/by/4.0/), which permits unrestricted use, distribution, and reproduction in any medium, provided you give appropriate credit to the original author(s) and the source, provide a link to the Creative Commons license, and indicate if changes were made. 
depending on ceramics opacity [1]. Thus, resin cement is the material of choice in the cementation of ceramic veneers.

The material is available in pre-sintered blocks for chairside milling using CAD/CAM systems [3]. Lithium disilicate restorations can also be manufactured based on the lostwax, pressed ceramic technique [4]. The pressed system enables a smaller marginal gap between restoration margin and the finishing line in tooth preparation, besides being significantly stronger than other systems [4]. However, there is growing demand for the milled ceramic system, which enables intraoral digital impressions and in-office milling, thus reducing its production time [4]. Resin cement polymerization can be affected by some factors linked to the restoration, among them: ceramic thickness, color and type, crystalline structure, grain size, defects, intrinsic porosity and stratification technique [5-7]. However, few studies $[8,9]$ have shown that the difference in ceramic opacity influences the properties of resin cements.

Thus, the aim of this study was to evaluate the degree of conversion (DC) of lightcured resin cement subjected to activation through the interposition of lithium disilicate ceramic produced through two manufacturing techniques. The null hypothesis was that the degree of conversion (DC) of light-cured resin cement is not influenced by the two manufacturing techniques (CAD/CAM or Press).

\section{Methods}

\section{Specimen preparation}

Two discs (10 mm diameter; $0.6 \mathrm{~mm}$ thick) were made of lithium disilicate glass ceramics. The first one (pressed ceramic technique) consisted in isostatic injection based on the heat technology (IPS e.max Press, shade LT A1, Ivoclar Vivadent, Schaan, Liechtenstein). The other disc was based on the manufacturing technique applied to indirect restorations made of lithium disilicate ceramics, which followed the automation technique guided by the CAD/CAM system (IPS e.max CAD/CAM, shade LT A1, Ivoclar Vivadent, Schaan, Liechtenstein), whose milled ceramic discs were produced by scaninng the pressed ceramic disc with CEREC Omnicam (Sirona, Bensheim, Germany) from and milling it on CEREC MC-XL (Sirona). The resulting discs (both surfaces-top and bottom) were subjected to sequential wet polishing $\mathrm{SiC}$ abrasive papers (320, 400, 600 and 1200 grit; Norton SA, São Paulo, SP, Brazil) in a water-cooled automatic polisher (APL4; Arotec, Cotia, SP, Brazil) in order to get to final diameter $10 \mathrm{~mm}$ and thickness $0.5 \mathrm{~mm}$. Specimens were ultrasonically cleaned with distilled water for $10 \mathrm{~min}$ and dried with compressed air. Disc thickness was measured with $0.01 \mathrm{~mm}$-accuracy digital caliper (Mitutoyo Corporation, Tokyo, Japan).

The LED (light emitting diode) curing unit output (Radii Cal; SDI, Bayswater, Victoria, VIC, Australia) was measured with a power meter [10] (Ophir Optronics Inc., Danvers, MA, USA) at irradiance $1400 \mathrm{~mW} / \mathrm{cm}^{2}$. The irradiance was measured when the light-guide end touched the surface of the ceramics during exposure at $1260 \mathrm{~mW} / \mathrm{cm}^{2}$ (IPS e.max CAD/CAM) and $1120 \mathrm{~mW} / \mathrm{cm}^{2}$ (IPS e.max Press). The Rely $\mathrm{X}^{\mathrm{TM}}$ Veneer (3 M ESPE, shade A1, St. Paul, MN, EUA) light-cured resin cement was inserted in a matrix (1.0 $\mathrm{mm}$ thick; $7 \mathrm{~mm}$ diameter) and, then, the ceramic disc resulting from each manufacturing method was placed over the resin cement. The tip of the light curing unit was 
placed over the ceramic disc and the resin cement was light-activated for $20 \mathrm{~s}$. Five specimens were prepared for each manufacturing technique.

\section{Degree of conversion measurement}

Samples were manufactured in two different ways and divided in two groups: CAD/ CAM ceramic group $(n=5)$ and Press ceramic group $(n=5)$, for conversion degree analysis. Specimens were washed in distilled water, dried with absorbent paper, placed in black containers filled with distilled water and stored at $37^{\circ} \mathrm{C}$ for $24 \mathrm{~h}$.

The unpolymerized resin cement was accessed twice before all ten evaluations in order to set the bonding pattern of its monomeric state before sample analysis. The top of the specimens was analyzed through attenuated total reflectance Fourier transform infrared (ATR-FTIR) (Spectrum 100 Optica; Perkin Elmer, Waltham, MA, USA).

Graphs were generated in the Spectrum software version 6.3.1 (PerkinElmer) for visualization and analysis purposes. The ATR-FTIR spectrometer operated under the following conditions: $300-4000 \mathrm{~cm}^{-1}$ wavelength, $4 \mathrm{~cm}^{-1}$ resolution and 16 scans. The degree of conversion was based on the peak intensity of the aliphatic $\mathrm{C}=\mathrm{C}$ bond $\left(1608 \mathrm{~cm}^{-1}\right) /$ peak intensity of the aromatic $\mathrm{C}=\mathrm{C}$ bond $\left(1608 \mathrm{~cm}^{-1}\right)$ ratio, which was calculated for cured and uncured specimens through the following equation:

$$
\mathrm{DC}=(1-\mathrm{R} \text { cured } / \mathrm{R} \text { uncured }) \times 100 .
$$

where $\mathrm{R}$ is previously described peak.

These calculations were performed in Microsoft Office Excel 2007 software (Microsoft Office Professional Edition 2007, Microsoft Corporation).

\section{Statistical analysis}

Data were subjected to statistical analysis in the SAS System for Windows 9.0 (SAS Institute Inc., Cary, NC, USA). Degree of conversion values were subjected to ANOVA and Student's t-test, at $5 \%$ significance level.

\section{Results}

Table 1 shows the mean degree of conversion values (power of statistical test, 0.99). The degree of conversion of Rely $\mathrm{X}^{\mathrm{TM}}$ Veneer was statistically higher in the CAD/CAM manufacturing technique $(39.83 \pm 0.35 \%)$ than in the Press technique $(37.59 \pm 0.62 \%)$.

\section{Discussion}

Successful cementation and restoration procedures depend on the strong and durable bond among resin cement, ceramics and dental structure [9]. The adhesion strength is directly proportional to the suitable cement polymerization and it is crucial to enable

Table 1 Degree of conversion (\%) of resin cement (mean \pm SD)

\begin{tabular}{lc}
\hline Ceramic group & Resin cement \\
\hline CAD/CAM & $39.83(0.35) \mathrm{A}$ \\
Press & $37.59(0.62) \mathrm{B}$ \\
\hline
\end{tabular}

Different letters indicate statistically significant differences in the mean values (Student's t-test; $p<0.001$ ) 
the satisfactory physical, mechanical and clinical performance of resinous materials [11]. Few studies $[12,13]$ have evaluated the influence of translucency on the degree of conversion of luting materials. Some authors $[14,15]$ investigated the light transmission and degree of conversion of the resin cement, although based on different ceramic shades and thickness. Thus, this study assessed the degree of conversion of a light-cured resin cement in two different ceramic systems, namely: Press and CAD/CAM.

Proper polymerization is important to determine the longevity of ceramic restorations [12]. Incomplete polymerization can lead to color instability [15], residual monomer toxicity [16], decreased adhesion strength [17] and postoperative sensitivity, as well as to increased risk of micro infiltration and caries [18]. In clinical terms, the correct resin cement polymerization helps maintaining physical properties of the cement and affects ceramic restoration outcomes. Based on our results, the ceramic type (Press or CAD/ CAM) significantly influenced the degree of conversion of the resin cement.

It is known that resin cement polymerization can be affected if light does not reach the cement [19] - thickness and shade are some of the factors capable of hindering the polymerization process $[20,21]$. Therefore, the current study only used slides with similar ceramic thickness $(0.5 \mathrm{~mm})$ and shade (LT A1) to prevent these factors from interfering in the degree of conversion of the resin cement. The distance between the light source and the cement layer, as well as source type, light irradiance and exposure time are other factors capable of influencing the degree of conversion [9, 22]. These factors were standardized in our study to avoid biases. Thus, ceramic sheets were glued to the photopolymerizing apparatus to avoid differences in the distance between the ceramic type and the light; the same light curing unit $\left(1400 \mathrm{~mW} / \mathrm{cm}^{2} \mathrm{LED}\right)$ and exposure time (20 s) were adopted for the light-cured resin cement. However, irradiance after the interposition of the ceramic discs was attenuated to $1280 \mathrm{~mW} / \mathrm{cm}^{2}$ in the CAD/CAM ceramic group and to $1120 \mathrm{~mW} / \mathrm{cm}^{2}$ in the Press ceramic group. It may have been the factor leading to the difference in the degree of conversion observed in our study.

During indirect restoration luting, the ceramic attenuates the light intensity and reduces the amount of photons that reach the resin-based cement $[4,12]$. Thus, dualcured resin cements are indicated to compensate the light attenuation caused by the interposition of an indirect restorative material, as well as to assure proper resin cement polymerization processes [23]. However, the light-cured cement used in the current study has received sufficient energy to enable polymerization. According to Burgess et al. [24], $16 \mathrm{~J} / \mathrm{cm}^{2}$ is the minimum energy density to be applied; thus, the present study adopted energy density $25.6 \mathrm{~J} / \mathrm{cm}^{2}$ in the CAD/CAM system and $22.4 \mathrm{~J} / \mathrm{cm}^{2}$ in the Press system. Thus, energy density was not a limiting factor for Press system. However, it is necessary conducting further studies based on energy density equivalence to validate this assumption.

The degree of conversion was analyzed through Fourier transform infrared spectroscopy-(FTIR); the CAD/CAM ceramic group showed statistically significant higher difference in the degree of conversion than the Press ceramic group when Rely $\mathrm{X}^{\mathrm{TM}}$ Veneer resin cement was used. Differences in ceramic translucency affect the degree of conversion of the cement; in addition, high-translucency ceramics present higher degree of conversion of the cement than the low-translucency ones [13]. As discs with similar shade, thickness and manufacturer were used in the current study, the CAD/CAM 
system appeared to present higher translucency; however, it is necessary conducting further studies to assess this property. Moreover, Alkadi and Ruse [25] reported different crystal sizes formed during the processing of each technique. Thus, material translucency may have been affected by the size of the crystals. Therefore, according to our results, the null hypothesis was rejected because the DC of light-cured resin cement was influenced by the manufacturing techniques.

\section{Conclusion}

Based on the herein adopted methodology and materials and on the results obtained in this study, it was possible concluding that:

The light-cured resin cement activated through ceramic structure reinforced with lithium disilicate generated through the CAD/CAM manufacturing technique showed higher degree of conversion than the one generated through the Press manufacturing technique.

\section{Abbreviations}

ATR-FTIR: attenuated total reflectance Fourier transform infrared; CAD/CAM: computer-aided design/computer-aided manufacturing; DC: degree of conversion; LED: light emitting diode.

\section{Authors' contributions}

$A C D, A H M G$, and MBL participated in performing the experiments. SBB, GGJ and LLS contributed to the writing of the manuscript. IOFD performed the statistical analysis. RDG conceived of the study, participating in its design and coordination, helping to drafting the manuscript. All authors read and approved the final manuscript.

\section{Acknowledgements}

The authors thank Laboratório Miranda (Belo Horizonte—MG/Brazil) for assisting in laboratory work.

\section{Competing interests}

The authors declare that they have no competing interests.

Availability of data and materials

Not applicable.

Funding

Not applicable.

\section{Publisher's Note}

Springer Nature remains neutral with regard to jurisdictional claims in published maps and institutional affiliations.

Received: 18 September 2018 Accepted: 10 November 2018

Published online: 16 November 2018

\section{References}

1. Archegas LR, de Menezes Caldas DB, Rached RN, Soares P, Souza EM. Effect of ceramic veneer opacity and exposure time on the polymerization efficiency of resin cements. Oper Dent. 2012;37:281-9.

2. Runnacles P, Correr GM, Baratto Filho F, Gonzaga CC, Furuse AY. Degree of conversion of a resin cement light-cured through ceramic veneers of different thicknesses and types. Braz Dent J. 2014;25:38-42.

3. Hamza TA, Ezzat HA, El-Hossary MMK, El Megid Katamish HA, Shokry TE, Rosenstiel SF. Accuracy of ceramic restorations made with two CAD/CAM systems.J Prosthet Dent. 2013;109(2):83-7.

4. Azar B, Eckert S, Kunkela J, Ingr T, Mounajjed R. The marginal fit of lithium disilicate crowns: press vs. CAD/CAM. Braz Oral Res. 2018;32:e001.

5. Bansal R, Taneja S, Kumari M. Effect of ceramic type, thickness, and time of irradiation on degree of polymerization of dual_cure resin cement. J Conserv Dent. 2016;19:414-8.

6. Rasetto FH, Driscoll CF, Prestipino V, Masri R, von Fraunhofer JA. Light transmission through all-ceramic dental materials: a pilot study. J Prosthet Dent. 2004;91:441-6.

7. Ilie N, Hickel R. Correlation between ceramics translucency and polymerization efficiency through ceramics. Dent Mater. 2008;24:908-14.

8. Linden JJ, Swift EJ Jr, Boyer DB, Davis BK. Photo-activation of resin cements through porcelain veneers. J Dent Res. 1991;70:154-7. 
9. Uctasli S, Hasanreisoglu U, Wilson HJ. The attenuation of radiation by porcelain and its effect on polymerization of resin cements. J Oral Rehabil. 1994;21:565-75.

10. Grandi VH, Berger SB, Fugolin APP, Gonini-Júnior A, Lopes MB, Consani S, Guiraldo RD. Microtensile bond strength and microhardness of composite resin restorations using a sonic-resin placement system. Braz Dent J. 2017;28:618-23.

11. Mowafy OM, Rubo MH, Badrawy WA. Hardening of new resin cements cured through a ceramic inlay. Oper Dent. 1999:24:38-44

12. Noronha Filho JD, Brandão NL, Poskus LT, Guimarães JG, Silva EM. A critical analysis of the degree of conversion of resin-based luting cements. J Appl Oral Sci. 2010;18:442-6.

13. Oh S, Shin SM, Kim HJ, Paek J, Kim SJ, Yoon TH, Kim SY. Influence of glass-based dental ceramic type and thickness with identical shade on the light transmittance and the degree of conversion of resin cement. Int J Oral Sci. 2018;10:5.

14. Meng X, Yoshida K, Atsuta M. Influence of ceramic thickness on mechanical properties and polymer structure of dual-cured resin luting agents. Dent Mater. 2008;24:594-9.

15. Janda R, Roulet JF, Kaminsky M, Steffin G, Latta M. Color stability of resin matrix restorative materials as a function of the method of light activation. Eur J Oral Sci. 2004;112:280-5.

16. Goldberg M. In vitro and in vivo studies on the toxicity of dental resin components: a review. Clin Oral Investig. 2008;12:1-8.

17. Novais VR, Raposo LH, Miranda RR, Lopes CC, Simamoto Júnior PC, Soares CJ. Degree of conversion and bond strength of resin-cements to feldspathic ceramic using different curing modes. J Appl Oral Sci. 2017;25:61-8.

18. De Souza G, Braga RR, Cesar PF, Lopes GC. Correlation between clinical performance and degree of conversion of resin cements: a literature review. J Appl Oral Sci. 2015;23:358-68.

19. Reza F, Lim SP. Effects of curing mode of resin cements on the bond strength of a titanium post: an intraradicular study. J Conserv Dent. 2012;15:123-6.

20. Öztürk E, Chiang YC, Coşgun E, Bolay Ş, Hickel R, Ilie N. Effect of resin shades on opacity of ceramic veneers and polymerization efficiency through ceramics. J Dent. 2013;41(Suppl 5):e8-14.

21. Soares CJ, da Silva NR, Fonseca RB. Influence of the feldspathic ceramic thickness and shade on the microhardness of dual resin cement. Oper Dent. 2006;31:384-9.

22. Ilie N. Transmitted irradiance through ceramics: effect on the mechanical properties of a luting resin cement. Clin Oral Investig. 2017;21:1183-90.

23. Lee IB, Um CM. Thermal analysis on the cure speed of dual cured resin cements under porcelain inlays. J Oral Rehabil. 2001;28:186-97.

24. Burgess JO, Walker RS, Porche CJ, Rappold AJ. Light curing —an update. Compend Contin Educ Dent. 2002;23:889-92894896.

25. Alkadi L, Ruse ND. Fracture toughness of two lithium disilicate dental glass ceramics. J Prosthet Dent. 2016;116:591-6.

\section{Submit your manuscript to a SpringerOpen ${ }^{\circ}$ journal and benefit from:}

- Convenient online submission

Rigorous peer review

- Open access: articles freely available online

- High visibility within the field

Retaining the copyright to your article

Submit your next manuscript at $\boldsymbol{\nabla}$ springeropen.com 